\title{
Performance of a bridge deck as solar collector in a thermal energy storage system
}

\author{
$D i \mathrm{Wu}^{1}$; Gangqiang Kong ${ }^{2 *}$, Hanlong $\mathrm{Liu}^{3 *}, X i \mathrm{Zhu}^{2}$, and Hefu $\mathrm{Pu}^{4}$ \\ ${ }^{1}$ Qingdao University of Technology, School of Science, Qingdao, China. \\ ${ }^{2}$ Hohai University, College of Civil and Transportation Engineering, Nanjing, China. \\ ${ }^{3}$ Chongqing University, Collage of Civil Engineering, Chongqing, China. \\ ${ }^{4}$ Huazhong University of Science and Technology, School of Civil Engineering and Mechanics, Wuhan, China.
}

\begin{abstract}
Solar energy can be stored in subsurface and extracted to melt snow and deice in winter. In summer, the bridge deck heat element in a bridge deicing system could serve as a solar energy collector without additional cost. Numerical models were developed in this study to investigate the performance of a bridge deck solar collector. The effects of radiation intensity and wind speed on the solar energy collection efficiency of a bridge deck solar energy collector were discussed and analyzed. The results show that the temperature of the slab was decreased during the solar collection process, and the solar energy collection efficiency of the bridge deck solar collector was about $26 \sim 47 \%$. The collection efficiency of solar energy at a given wind speed was increased with the decreasing of the radiation energy, and this effect was more pronounced when the wind speed was higher. The solar energy collection was beneficial to the durability of the top asphalt layer as well as the structural response of the bridge because the magnitude and gradient of the slab temperature were much lower when the bridge deck served as a solar energy collector.
\end{abstract}

\section{Introduction}

Snow accumulation is usually removed by a combination of the use of deicing salt and mechanical removal. However, deicing salt may lead to alkali-aggregate reactions in concrete as well as environmental issues. The subsurface soil and rock could be served as a heat source because the temperature of the ground remains relatively constant throughout the year $[1,2]$, and ground heat pump systems (GHPS) have been widely employed to extract geothermal energy in recent years [3]. Therefore, the adverse effects caused by conventional deicing methods could be ameliorated by extracting geothermal energy for bridge deck heating.

The pile foundations could be served as heat exchangers [2, 4], and the combination of a GHPS and pile heat exchangers could provide us with an economical way to extract shallow geothermal energy because no boreholes are need to be drilled additionally. There are some applications of bridge deck heating using geothermal energy [4-9]. However, most of these cases employed geothermal boreholes as heat exchangers, and few cases using pile heat exchangers [4,9]. Miyamoto and Takeuchi [4] proposed an energy pile based bridge snow-melting system in Fukui Prefecture, Japan. There are 32 steel piles with a spacing of $1.5 \mathrm{~m}$ were used as heat exchangers, and the total length of these 32 piles was $1,300 \mathrm{~m}$. Bowers and Olgun [9] performed a field test at Virginia Tech Geotechnical Research Facility. A micro pile of $0.25 \mathrm{~m}$ in diameter and $30.5 \mathrm{~m}$ in length was equipped with heat exchange loops, which were connected to a prototype $2.4 \mathrm{~m} \times 3.0 \mathrm{~m}$ bridge deck.

A geothermal energy deicing system for bridge decks using a pile heat exchanger was developed by Kong et al. [10]. No heat pump was used in this system and the performance of this system was investigated under the conditions of snowfall. It was found that the deicing system using a pile heat exchanger could be employed for accelerating the snow-melting process. However, the energy extracted by the energy pile was not sufficient to remove the snowfall immediately when it accumulated on the bridge deck. Soil-borehole thermal energy storage systems are typically used to store heat collected from renewable sources [11-13]. The deicing system for bridge decks using pile heat exchangers may provide us with an economical way to store heat in subsurface because the bridge deck with an energy pile could be regarded as a solar energy collector which could collect and store the solar energy in summer. The solar energy stored in the ground could be then extracted for bridge deck deicing more efficient in winter. Therefore, the energy demand issue that encountered in the previous study [10] may be resolved if the above assumption is feasible.

The performance of a solar energy storage system using pile heat exchangers is determined by two factors: 1) the solar energy collection efficiency of the solar collector; 2) the heat exchange rate of the pile heat exchanger. A number of case studies have been carried out to investigate the heat exchange performance of pile

\footnotetext{
* Corresponding author: gqkong1@163.com; hliuhhu@163.com
} 
heat exchangers. However, the solar energy collection efficiency of a bridge deck solar energy collector has not been studied. In this study, the performance of a bridge deck solar collector was investigated numerically. The temperature variation of the slab and the circulating fluid during the solar energy collection process was analyzed. Additionally, the effects of radiation intensity and wind speed on the solar energy collection efficiency of a bridge deck solar energy collector were also studied.

\section{Numerical modeling}

A series of 3D numerical analyses were performed through the finite element software COMSOL to investigate the solar energy collection performance of a bridge when it is served as a solar collector. The geometry of the bridge deck as well as the pipe configuration of the solar energy collector developed in the numerical models was identical to the deicing system that was proposed by Kong et al. [10]. The bridge is 36 $\mathrm{m}$ in length and $26 \mathrm{~m}$ in width. Polyethylene of raised temperature resistance (PERT) tubes with inner and outer diameters of 16 and $20 \mathrm{~mm}$ were used as heat exchanger tubes, which were embedded in a cast-inplace reinforced concrete layer of the bridge deck with a concrete cover of $40 \mathrm{~mm}$ in thickness. The first span slab of the bridge was embedded with the heat exchanger tubes, and the layout of the pipe configuration and the bridge deck is presented in Fig. 1.

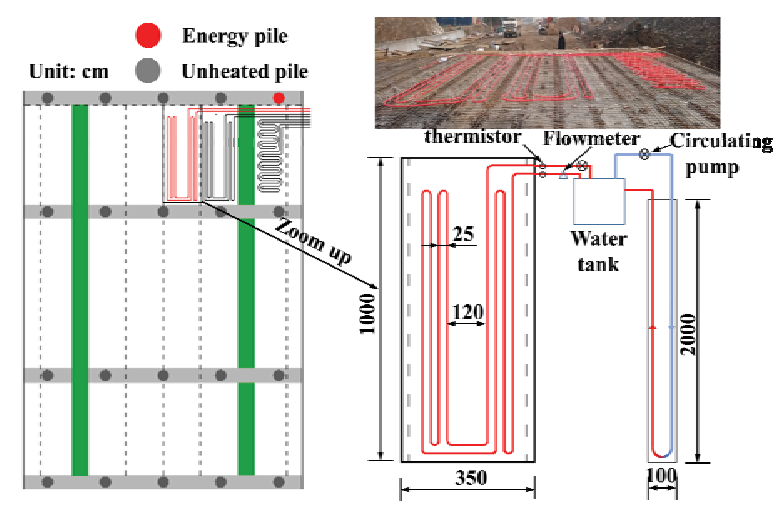

(a)
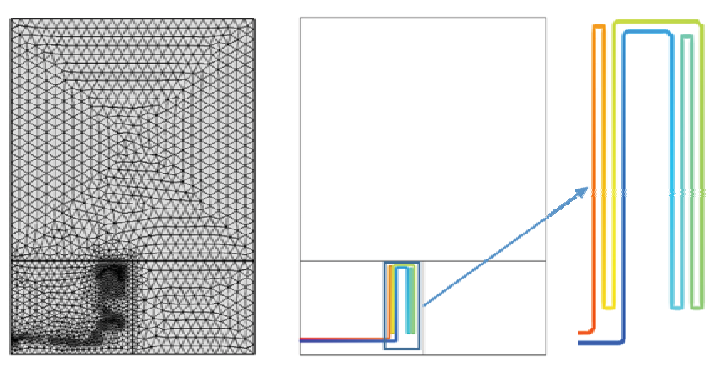

(b)

Fig. 1. Layout of the heat exchanger pipe and the bridge deck: (a) system developed by Kong et al. [10]; (b) Numerical modeling.
Table 1. The summary of numerical analysis categories

\begin{tabular}{|c|c|c|}
\hline $\begin{array}{c}\text { Wind } \\
\text { speed } V \\
(\mathrm{~m} / \mathrm{s})\end{array}$ & $\begin{array}{c}\text { Max. radiation } \\
\text { energy } A \\
\left(\mathrm{~W} / \mathrm{m}^{2}\right)\end{array}$ \\
\hline 0 & 400 & \\
\hline 1 & 600 & \\
\hline 2 & 800 \\
\hline 3 & 1000 & \\
\hline 4 & 1200 & \\
\hline
\end{tabular}

The category of numerical analyses in this study was summarized in Table 1. The analyses considered a variety of radiation intensity and wind speed. Variation of these parameters allowed us to estimate the effects of different factors on the solar energy collection performance of the bridge deck solar energy collector. It should be noted that the duration of the solar energy collection process in each model is 12 hours, which corresponds to the sunrise and sunset (7:00 19:00) in summer, China. The trend of the ambient temperature and radiation intensity in a solar energy collecting day is governed by a sinusoidal function [14], and the maximum value of the radiation intensity ranges from $400 \mathrm{~W} / \mathrm{m}^{2}$ to $1200 \mathrm{~W} / \mathrm{m}^{2}$. Saetta et al. [15] found that the heat exchange rate on an air-concrete interface could be affected by wind speed and the relationship between the convection heat exchange coefficient $\left(\alpha_{c}\right)$ on an airconcrete interface and wind speed $(V)$ is as follows:

$$
\alpha_{c}=5.6+4.0 V \text { for } V<5 \mathrm{~m} / \mathrm{s} ; \alpha_{c}=7.15 V^{0.78} \text { for } V<5 \mathrm{~m} / \mathrm{s}
$$

In this study, the range of variation in wind speed $\mathrm{V}$ is $0 \sim 5 \mathrm{~m} / \mathrm{s}$. The temperature $\left(20^{\circ} \mathrm{C}\right)$ and the velocity $(1.27 \mathrm{~m} / \mathrm{s})$ of the inlet fluid was kept constant throughout the analysis.

Table 2. Summary of the material properties

\begin{tabular}{|l|c|c|c|c|}
\hline \multirow{2}{*}{ Property } & \multirow{2}{*}{ Concrete } & \multicolumn{3}{c|}{$\begin{array}{c}\text { Asphalt slab } \\
\text { (Wu et al. [16]) }\end{array}$} \\
\cline { 3 - 5 } & & $\begin{array}{c}\text { Top } \\
\text { layer }\end{array}$ & $\begin{array}{c}\text { Middle } \\
\text { layer }\end{array}$ & $\begin{array}{c}\text { Base } \\
\text { layer }\end{array}$ \\
\hline Densigy $\left(\mathrm{kg} / \mathrm{m}^{3}\right)$ & 2500 & 2000 & 2000 & 2000 \\
\hline $\begin{array}{l}\text { Heat Capacity } \\
\left(\mathrm{J} /\left(\mathrm{kg} \cdot{ }^{\circ} \mathrm{C}\right)\right)\end{array}$ & 1000 & 1680 & 1680 & 1680 \\
\hline $\begin{array}{l}\text { Thermal Conductivity } \\
\left(\mathrm{W} /\left(\mathrm{m} \cdot{ }^{\circ} \mathrm{C}\right)\right)\end{array}$ & 1.9 & 1.73 & 1.73 & 1.89 \\
\hline Surface Emissivity & 0.5 & 0.6 & 0.6 & 0.6 \\
\hline
\end{tabular}

A heat transfer with surface to surface radiation boundary was applied to the top surface of the bridge deck in order to simulate the thermal response of a bridge deck during a solar energy collection process. An external radiation source in a direction perpendicular to the top surface of the bridge deck was employed to simulate the solar radiation. Moreover, the effect of ambient temperature changes as well as the heat convection exchange of the wind was accounted by a heat flux boundary condition applied on all surfaces of the bridge deck. The mesh is refined close to the heat exchanger pipes as presented in Fig. 1. 
Wu et al. [16] investigated the thermal response of asphalt pavements as solar collector by application of small-scale asphalt slabs in laboratory. The test results were referred in this study and a verification model was also developed, and a comparison between the experimental results and numerical results was made for model verification. The diagram figure of the asphalt slab was presented in Fig. 2. The inlet temperature was $20{ }^{\circ} \mathrm{C}$, and the radiation intensity was $1200 \mathrm{~W} / \mathrm{m}^{2}$. The wind speed was $0 \mathrm{~m} / \mathrm{s}$. Properties of the materials used in the numerical analyses are summarized in Table 2.
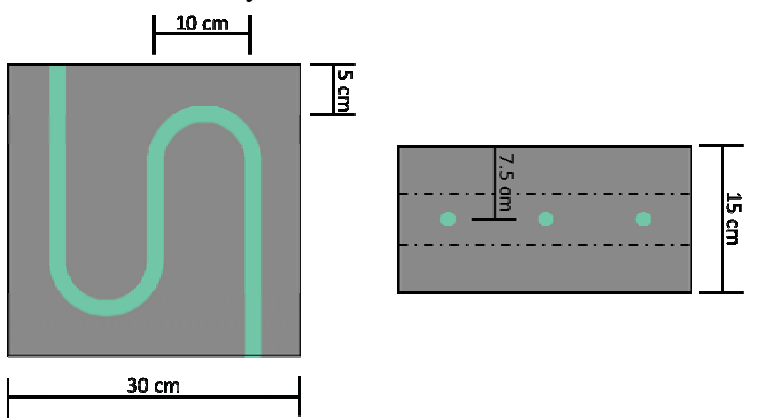

(a)

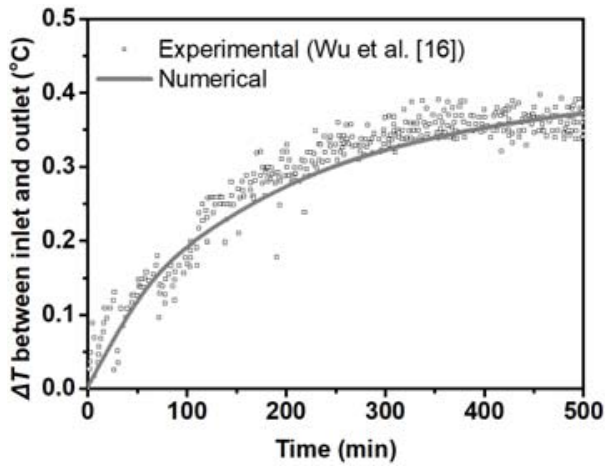

(b)

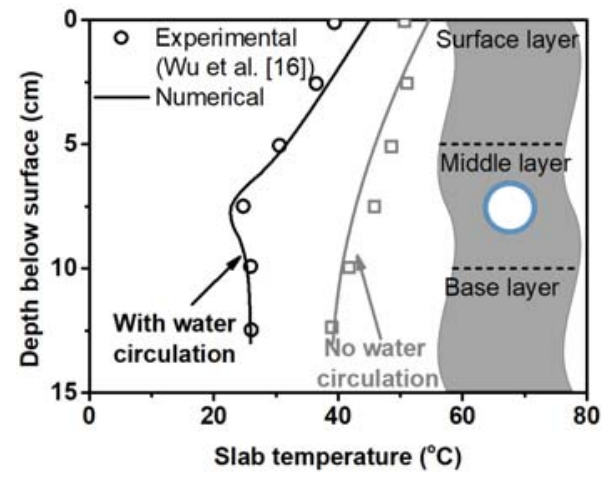

(c)

Fig. 2. Comparison between the numerical results and experimental results obtained by $\mathrm{Wu}$ et al. [16]: (a) schematic diagram of slab; (b) $\Delta T$ between inlet and outlet; (c) slab temperature.

\section{Results and Discussion}

Comparison between the numerical results and experimental results obtained by $\mathrm{Wu}$ et al. [16] are presented in Fig. 2. As indicated in Fig. 2 that the temperature difference of the circulating fluid between the inlet and outlet increased as the irradiation time increase, and an increment in $\Delta T$ of $0.37{ }^{\circ} \mathrm{C}$ was observed. The temperature profiles of the slab that were determined experimentally and numerically were also shown in Fig. 2. Compared to the slab with no water circulation, the temperature of the slab with water circulation was lower, especially at locations next to the pipes. It indicates that solar energy could be extracted from the asphalt slab by the circulating water. Similar phenomena were observed in both laboratory tests and the numerical simulation. The accordance between the experimental results and numerical results prove that the numerical model developed in this study could take the solar radiation and the heat transfer mechanism of a slab into account.

Fig. 3 shows the variations in temperature of the inlet and outlet fluid under different radiation energy and wind speed. Under a constant inlet temperature of $20^{\circ} \mathrm{C}$, the outlet temperature increased gradually in the first 8 hours which is followed by a decrease in the last 6 hours. This can be attributed to the variation process of the radiation energy as well as the ambient temperature (see Table 1). The peak value of the radiation energy and ambient temperature occurred 6 hours after the solar collection began. However, the peak value of the outlet temperature was observed after 8 hours. The final value of the outlet temperature could not go back to its initial value at the end of the solar collection because of the heat storage of the concrete bridge deck induced by the solar irradiation.

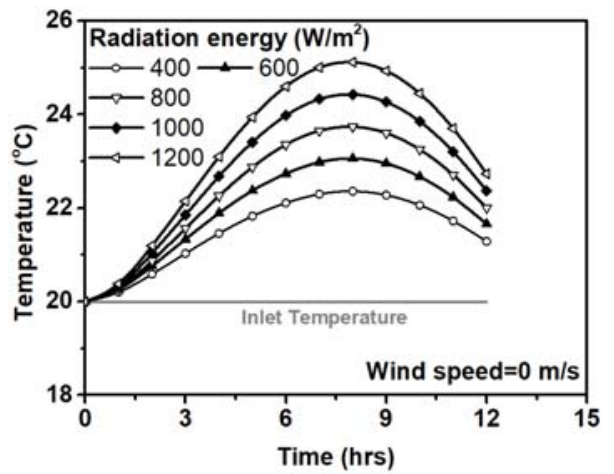

(a)

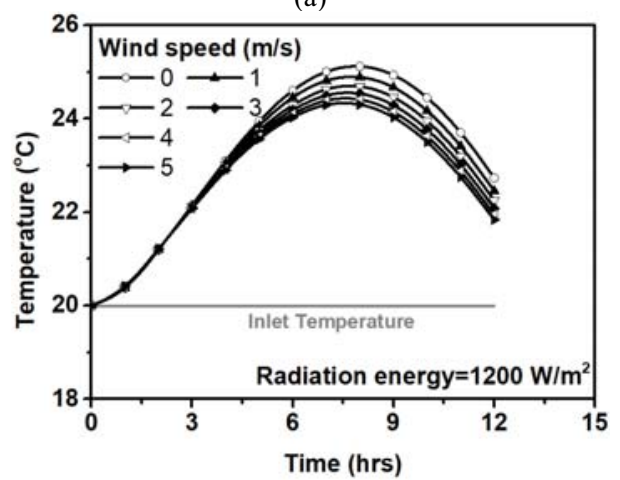

(b)

Fig. 3. Variations in temperature of the inlet and outlet fluid under different: (a) radiation energy; (b) wind speed. 
As presented in Fig. 3(a), a higher outlet temperature could be observed under a higher radiation energy. Under radiation energy of $400 \mathrm{~W} / \mathrm{m}$, the maximum value of the outlet temperature was about $22{ }^{\circ} \mathrm{C}$. The maximum outlet temperature increased by about $3{ }^{\circ} \mathrm{C}$ when the radiation energy grew up to $1200 \mathrm{~W} / \mathrm{m}$. The effects of the convective heat transfer of the slab could be enhanced under a higher wind speed, which leads to the heat loss of the bridge deck. Therefore, the temperature of the circulating fluid decreased with the wind speed increase as indicated in Fig. 3(b).

The temperature difference between the inlet and outlet of the circulating fluid from the bridge deck directly reflects the solar energy collection ability of the bridge deck. Therefore, the solar energy collection efficiency of the bridge deck used in this study could be determined by the following method [14]:

$$
\eta=\frac{m c_{p} \Delta T}{q_{\text {solar }} A_{\text {slab }}}
$$

where $m$ and $c_{p}$ is the mass flow rate and heat capacity of the circulating fluid, $\mathrm{kg} / \mathrm{s}$ and $\mathrm{J} /\left(\mathrm{kg} \cdot{ }^{\circ} \mathrm{C}\right)$, respectively; $\Delta T$ is the of the temperature different between the inlet and outlet, ${ }^{\circ} \mathrm{C} ; q_{\text {solar }}$ is the solar energy intensity, $\mathrm{W} / \mathrm{m}^{2} ; A_{\text {slab }}$ is the area of solar collection zone within a bridge deck, $\mathrm{m}^{2}$.

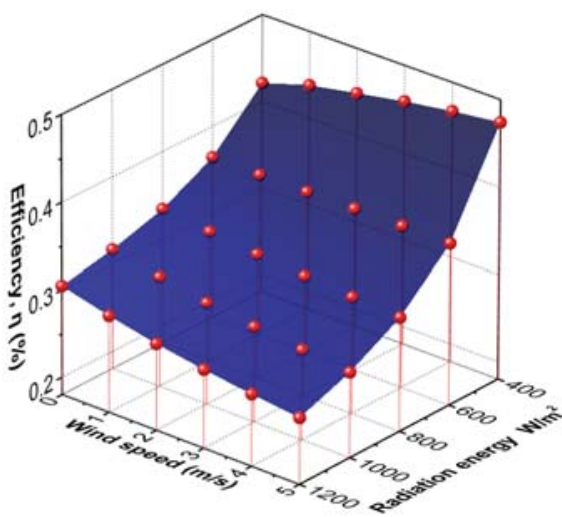

Fig. 4. Maximum solar energy collection efficiency of the bridge deck under different climate conditions.

By using Equation (2), the maximum solar energy collection efficiency of the bridge deck under different climate conditions is indicated in Fig. 4. The results in Fig. 4 show that the solar energy collection efficiency of a bridge deck solar collector was about $26 \sim 47 \%$. Moreover, the collection efficiency of solar energy at a given wind speed was increased with the decreasing of the radiation energy, and this effect was more pronounced when the wind speed was higher. At a given radiation energy level, the trend of the maximum collection efficiency of the solar energy varied with the wind speed was not identical. For instance, the solar energy collection was more efficient under a higher wind speed (e.g. $5 \mathrm{~m} / \mathrm{s}$ ) when the radiation energy was 400 $\mathrm{W} / \mathrm{m}^{2}$. However, the solar energy collection efficiency decreased with increasing the wind speed when the radiation energy was much higer (i.e. $1200 \mathrm{~W} / \mathrm{m}^{2}$ ). These results could be attributed to the comprehensive effects of the heat convective exchange of the ambient and the heat transfer induced by solar radiation.

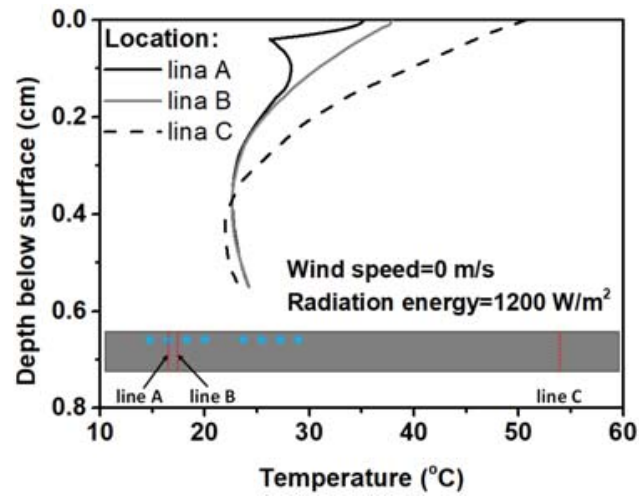

(a)

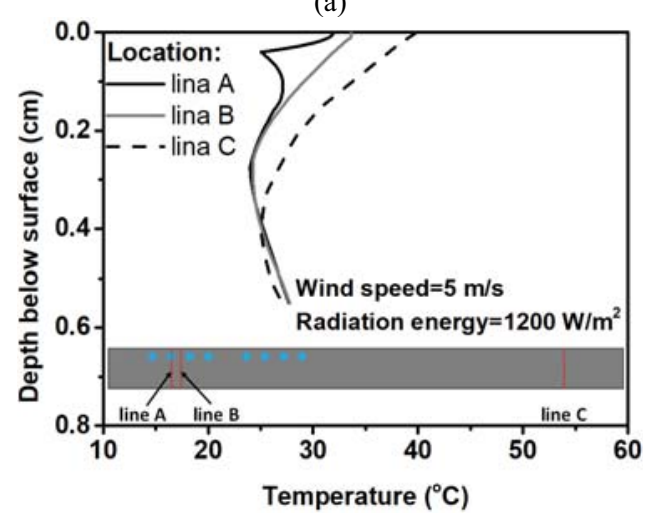

(b)

Fig. 5. Temperature profiles of the bridge deck.

The temperature profiles of the bridge deck are presented in Fig. 5. The results in Fig. 5 show that the surface temperature of the slab close to the pipes was lower than the surface temperature observed far away from the pipes, especially when the wind speed was lower. A decrease in surface temperature close to the pipes of about $10{ }^{\circ} \mathrm{C}$ could be found when the wind speed was $0 \mathrm{~m} / \mathrm{s}$. This results could be attributed to the energy extraction caused by the heat carrier fluid, and was beneficial to the durability of the top asphalt layer of the bridge. Moreover, the temperature gradient that varies with the depth of the bridge deck was much lower when the heat exchange water was circulating. This phenomenon means that the solar collection process of a bridge deck was advantageous to its structural response because the thermal stress of the concrete slab induced by the uneven slab temperature distribution maybe lower when the bridge deck served as a solar collector.

\section{Conclusions}

The performance of a bridge deck solar energy collector was investigated numerically. The effects of radiation intensity and wind speed on the solar energy collection efficiency of a bridge deck solar energy collector were 
analyzed. There are several finds that can be drawn from the numerical analyses presented in this study.

1) The outlet temperature of the circulating fluid was increased with the increasing of the radiation energy. The maximum outlet fluid temperature increased by about $3{ }^{\circ} \mathrm{C}$ when the radiation energy grew from 400 $\mathrm{W} / \mathrm{m}$ up to $1200 \mathrm{~W} / \mathrm{m}$. However, the effects of the convective heat transfer on the surface of the bridge deck could be enhanced under a higher wind speed, which leads to the heat loss of the bridge deck.

2) The solar energy collection efficiency of the bridge deck solar collector was about $26 \sim 47 \%$ in this study. The solar energy collection efficiency of a bridge deck solar energy collector could be affected by the comprehensive effects of the heat convective exchange of ambient and the heat transfer induced by solar radiation. The collection efficiency of solar energy at a given wind speed was increased with the decreasing of the radiation energy, and this effect was more pronounced when the wind speed was higher.

3) The solar energy collection was beneficial to the durability of the top asphalt layer as well as the structural response of the bridge because the magnitude and gradient of the slab temperature were much lower when the bridge deck served as a solar energy collector. For instance, a decrease in surface temperature close to the pipes of about $10^{\circ} \mathrm{C}$ could be found when the wind speed was $0 \mathrm{~m} / \mathrm{s}$

The work presented in this paper was supported by the National Natural Science Foundation of China (grant nos. 51922037, 51778212).

\section{References}

1. M.J. Economides. Engineering evaluation of geothermal reservoirs. Int. J. Energ. Res. 9(3), 299318 (2010).

2. H. Brandl. Energy foundations and other thermoactive ground structures. Géotechnique 56(2), 81122 (2006).

3. P.F. Healy and V.I. Ugursal. Performance and economic feasibility of ground source heat pumps in cold climate. Int. J. Energ. Res. 21(10), 857-870 (2015).

4. S. Miyamoto and M. Takeuchi. Snow-melting system on road using seasonal energy storage through foundation piles for bridge. Proceedings of JSCE 797, 51-62 (2005).

5. W.J. Eugster. Road and bridge heating using geothermal energy. overview and examples. Proceedings of European Geothermal Congress 1-5 (2007).

6. X. Liu, S.J. Rees and J.D. Spitler. Modeling snow melting on heated pavement surfaces. Part II: Experimental validation. Appl. Therm. Eng. 27(5), 1125-1131 (2007).

7. I. Yoshitake, N. Yasumura, M. Syobuzako, A. Scanlon. Pipe heating system with underground water tank for snow thawing and ice prevention on roads and bridge deck. J. Cold. Reg. Eng. 25(2), 7186 (2011).

8. N. Nagai, S. Miyamoto, T. Tsuda, S. Yamahata. Experimental xemonstrations and optimal design conditions of ssnow-melting system using geothermal and solar energy. Proceedings of Heat Transfer Summer Conference, 767-771 (2009).

9. G.A. Bowers, C.G. Olgun. Experimental investigation of bridge deck deicing using energy piles. Geotechnical Special Publication-ASCE, 1628-1637 (2015).

10. G. Kong, D. Wu, H. Liu, L. Laloui, X. Cheng, X. Zhu. Performance of a geothermal energy deicing system for bridge deck using a pile heat exchanger. Int. J. Energ. Res. 43(1), 596-603 (2019).

11. T. Başer, N. Lu, J.S. McCartney. Operational response of a soil-borehole thermal energy storage system. J. Geotech. Geoenviron. Eng. 142(4), 04015097 (2016).

12. T. Başer, Y. Dong, A.M. Moradi, N. Lu, K. Smits, S. Ge, D. Tartakovsky, and J.S. McCartney. Role of water vapor diffusion and nonequilibrium phase change in geothermal energy storage systems in the vadose zone. J. Geotech. Geoenviron. Eng. 144(7), 04018038 (2018).

13. T. Başer, and J.S. McCartney. Transient performance evaluation of solar thermal energy storage in a geothermal borehole array. Renew. Energ. 147, 2582-2598 (2020).

14. Q. Gao, Y. Huang, M. Li, Y. Liu, Y.Y. Yan. Experimental study of slab solar collection on the hydronic system of road. Sol. Energy. 84(12), 20962102 (2010).

15. A. Saetta, R. Scotta, R. Vitaliani. Stress analysis of concrete structures subjected to variable thermal loads. J. Struct. Eng. 121(3), 446-457 (1995).

16. S. Wu, M. Chen, J. Zhang. Laboratory investigation into thermal response of asphalt pavements as solar collector by application of small-scale slabs. Appl. Therm. Eng. 31(10), 1582-1587 (2011). 